\title{
Concentrate for Cutaneous Spray, Emulsion Dosage Form
}

National Cancer Institute

\section{Source}

National Cancer Institute. Concentrate for Cutaneous Spray, Emulsion Dosage Form. NCI

Thesaurus. Code C149385.

Liquid preparation intended to be diluted in the specified liquid to obtain a cutaneous spray emulsion. 